CARTA AL DIRECTOR

\title{
Agranulocitosis inducida por tratamiento combinado de clozapina y ácido valproico
}

\author{
R. Madeb ${ }^{b}$, S. Hirschmann ${ }^{\mathrm{a}, \mathrm{b}}$, R. Kurs ${ }^{\mathrm{b}}$, A. Turkie ${ }^{\mathrm{b}}, \mathrm{I}$. Modai ${ }^{\mathrm{a}, \mathrm{b}}$ \\ -Facultad de Medicina Bruce Rappaport, Technion, Haifa, Israel; 'Centro de Salud Mental Sha'ar Menashe, \\ Mobile Post Hefer 38814, Hadera, Israel
}

\section{Sr. Director:}

El ácido valproico (AVP) se utiliza cada vez más en psiquiatría. Las reacciones adversas hematológicas al AVP comunicadas en las publicaciones incluyen la anemia aplásica, la citopenia y los síndromes mielodisplásicos $[1,4,6,7]$. Nuestro informe describe a un paciente que desarrolló agranulocitosis después que se añadiera AVP a una terapia en curso de clozapina. El señor $C$., un paciente de 51 años con esquizofrenia paranoide crónica y anomalías del EEG (ondas theta frontales y centrales, y ondas lambda después de hiperventilación), fue tratado con éxito con $325 \mathrm{mg} /$ día de clozapina durante 3 años, pero no cumplió su régimen de tratamiento después del alta. Seis meses después fue readmitido en estado psicótico agudo, y se reanudó la clozapina (325 $\mathrm{mg} /$ día). El paciente estaba hostil y agresivo, con cambios del estado de ánimo. La adición de carbonato de litio redujo su agresividad. Dos meses después, el señor $C$. desarrolló signos de diabetes insípida, que remitieron después de la interrupción del litio. El aumento con $1.000 \mathrm{mg} /$ día de AVP se inició 10 semanas después de la admisión, y el señor $\mathrm{C}$. mejoró de manera estable, con reducción de la agresividad física, los cambios del estado de ánimo, la fuga de ideas y el estado paranoide.

Durante 3 años de seguimiento ordinario de la clozapina, la cifra de leucocitos del señor C. fluctuó entre 7.500-12.000 células por $\mathrm{mm}^{3}$ (intervalo nor- mal). Su cifra de leucocitos anterior al AVP era 8.100 células por $\mathrm{mm}^{3}$, y la de neutrófilos, 5.580 células por $\mathrm{mm}^{3}$ con una fórmula leucocítica normal. Durante el primer mes de tratamiento de AVP, las cifras seriales ordinarias de leucocitos revelaron cifras normales pero decrecientes de los leucocitos y la fórmula leucocítica. Un mes después de la iniciación del AVP, el señor C. se quejó de debilidad general. Su cifra de leucocitos era 1.600 células por $\mathrm{mm}^{3}$ y de neutrófilos, 50 células por $\mathrm{mm}^{3}$, y el señor $C$. fue transferido a un hospital general.

Se administró factor estimulante de colonias granulocíticas y monocíticas (GMC-SF). La cifra total de leucocitos del paciente subió a 56.000 células por $\mathrm{mm}^{3}$ y la de neutrófilos a 48.000 células por $\mathrm{mm}^{3}$, y luegó se estabilizaron en niveles normales (leucocitos: 7.650 células por $\mathrm{mm}^{3}$; neutrófilos: 4230 células por $\mathrm{mm}^{3}$ ).

El señor $C$. recibió entonces olanzapina (20 $\mathrm{mg} /$ día) y clonacepam ( $0,5 \mathrm{~g} /$ día); su estado mental se mantuvo estable y sus índices hematológicos permanecieron normales. Veintiuna semanas después su cifra de leucocitos era 8.000 células por $\mathrm{mm}^{3}$, y de neutrófilos, 4.200 células por $\mathrm{mm}^{3}$.

La incidencia de la agranulocitosis inducida por clozapina es $1-2 \%$, produciéndose el $80 \%$ de los casos en las 18 primeras semanas de terapia. Se ha comunicado la coadministración de clozapina y algunos anticonvulsionantes aromáticos (por ejemplo, carbamacepina) en el aumento de la toxicidad combinada sobre las células precursoras sanguíneas [5]. 


\section{-Dalparan}

1. NOMBRE DEL MEDICAMENTO. Dalparan. 2. COMPOSICIÓN CUALITATIVA Y CUANTITATIVA. Cada comprimido contiene: Zolpidem (DCI) hemitartrato, 10 mg. 3. FORMA FARMACEUTICA.Comprimidos recubiertos ranurados. 4. DATOS CLINICOS. 4.1. Indicaciones terapeuticas: Tratamiento a corto plazo del insomnio, Las benzodiacepinas to los agentes similares a las benzodiacepinas están indicados solamente cuando la alteración es grave, incapacitante o someposible. Generol ente la duración del tratomiento varia desde pocos dís a dos semanas, con un máximo, incluyendo el seríodo de disminución de đosis, de cuatro semanas. En ciertos casos puede ser necesaria una prolongación del periodo máximo de tratamiento; si esto ocurre, no se realizará sin una reevaluación del estado del paciente. El producto debe ser tomado justo antes de acostarse. Dosis: La dosis diaria recomendada para adultos es de $10 \mathrm{mg}$ inmediatamente antes de acostarse. En ancianos o pacientes debilitados que pueden ser especialmente sensibles a los efectos de zolpidem, y en pacientes con insuficiencia hepatica que no metabolizan el firmaco tan rapidamente como los individuos normales, se recomienda una dosis de $5 \mathrm{mg}$ que puede aumentarse soblo bajo circustancer Insuficiencia hepática grave. 4.4. Advertencias y precauciones especiales de empleo: Tolerancia: Tras su uso repetido durante unas semanas se puede desarrollar cierta pérdida de eficacia a los efectos hipnóticos de las benzodiacepinas de corta acción y de los agentes similares a las benzodiacepinas. Dependencia: El uso de benzodiacepinas o agentes similares a las benzodiacepinas puede conducir al desarrollo de dependencia física y psíquica a estos productos. El riesgo de dependencia aumenta con la dosis y la duración del tratamiento; es también mayor en pacientes con historia de abuso de alcohol o drogas. Una vez que se ha desarrollado dependencia fisica, la interrupción brusca del tratamiento producira sindrome de abstinencia

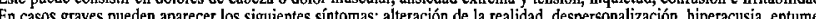
En casos graves pueden aparecer los siguientes síntomas: a ateración de la realidad, despersonalización, hiperacusia, entumesiones epilépticas. Insomnio de rebote: con la suspensión del tratamiento hipnótico puede ocurrir un sindrome transitorio por el que los sintomas que condujeron al tratamiento con una benzodiacepina, 0 agente similar a las benzodiacepinas, reapare cen de forma aumentada. Esto puede acompañasse de otras reacciones, incluyendo cambios de humor, ansiedade intranquilidad. El síndrome se desartolla más probablemente si el producto se suspendé de forma brusca, por lo que el tratamiento debe ser disminuido gradualmente. Duración del tratamiento: La duración del tratamiento debe ser tan corta como sea posible (ver 4.2. Posologia), sin exceder 4 semanas, inclayendo el periodo de disminución de dosis. La prolongación del tratamiento el tratamiento quéste sera de une duración limitada y explicar con precisión cómo se disminuirá progresivando comience Además es importante que se advierta al paciente de la posibilidad de fenómenos de rebote, minimizando por lo tanto la ansiedad sobre tales síntomas si aparecen mientras el producto esté siendo suspendido. Existen indicios de que, en el caso de las benzodiacepinas y agentes similares a las benzodiacepinas, con corta duración de acción, los fenómenos de suspensión pueden manifestarse dentro del intervalo de dosificación, especialmente cuando la dosis es alta. Amnesia: Las benzodiacepinas o los agentes similares a las benzodjacepinas pueden inducir amnesia anterograda. Esto ocurre más a menudo varias horas después de ingerir el producto y por consiguiente para reducir el riesgo los pacientes deben asegurarse de que podrán dormi ocurrir reacciones como intranguilidad, agitación, irritabilidad, agresividad, delirio, rabia, pesadillas, alucinaciones, psicosis, y ancianos. Grupos espece, el uso del producto debe ser suspendido. Estas reacciones ocurren más probablemente en niños prescribe zolpidem a pacientes con pacientes: Para ancianos, ver la dosis recomendada. Se debe tener precaución cuando judican la función respiratoria. Las benzodiacepinas y los agentes similares a benzodiacepinas están contraindicadas en pacientes con insuficiencia hepática grave ya que pueden precipitar encefalopatía. Las benzodiacepinas y los agentes similacepinas y los agentes similares a benzodiacepinas no deben ser empleados solos para tratar la depresión o la ansiedad aso(este tipo de pacientes). Las benzodiaceping podría precipitarse en este zodiacepinas deben ser utilizados con extrema precaución en pacientes con bistoria de abuso de alcolhol o drogas. Esta espe-
cialidad contiene lactosa. Se han descrito casos de intolerancia a este componente en niños y adolescentes. Aunque la cantidad presente en el preparado no es, probablemente, suficiente para desencedenar los sintomas de intolerancia, deberá tenerse en cuenta en caso de que aparecieran dianeas. 4.5. Interacción con otros medicamentos y otras formas de interacción: No
recomendada: Ingesta concomitante de alcohol. El efecto sedante puede ser aumentado cuando el producto es utilizado e recomendada: Ingesta concomitante de alcohol. El efecto sedante puede ser aumentado cuando el producto es utilizado en combinación con alcohol. Esto afecta la capacidad para conducir o utilizar maquinaria. Precaución: Combinación con depre-

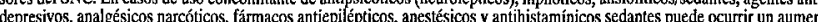
to del efecto depresivo central. En el caso de analésicos narcóticos podría producirse también un incremento de la euforia que conduce a un aumento de la dependencia psiquica. Los preparados que inhiben ciertas enzimas hepáticas (particularmente
el citocromo $\mathrm{P} 450$ ) pueden aumentar la actividad de las benzodiacepinas y de los agentes similares a las benzodiacepinas, 4.6. Embarazo y lactancia: No existen suficientes datos sobre zolpidem para evaluar su seguridad durante el embarazo y la laclancia. Si el producto es prescrito a una mujer en edad fértil, se le debe advertir que contacte con su médico para suspender cl tratamiento si pretende quedarse embarazada o si sospecha que lo esta. Si por razones médicas apremiantes, zolpidem es
administrado durante la úttlima fase del embarazo o durante el parto, se pueden esperar efectos en el neonato, como hipotermi hipotońa y moderaia depresión resintoria debilo a acción formecolo mia, hipotonía y moderada depresiún respiratoria, dento s la action farmacologica del producto. Por ofra parte, los niños mas fases del embarazo, pueden desartoillar dependencia física y puede existir algún riesgo de desarrollar síntomas de abstnencia en el periodo postnatal. Debido a que las benzodiacepinas y los agentes similares a las benzodiacepinas se excreta con la leche materna, no debe administrarse zolpidem a las madres dutante la lactancia. 4.7. Efectos sobre la capacidad para conducir vehículos y utilizar maquinaria: La capacidad para conducir o utilizar maquinana puede verse adversamente alterada debido a sedacion, amnesia, alteracion de la concentración y de la función musculart, $S_{1}$ la duración del sueño es suffciente, la posiblidad de alteración del estado de alerta puede aumentar (ver también 4.5. Interacciones). 4.8. Reacciones

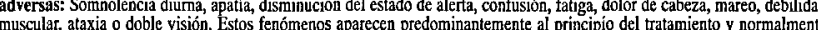
desaparecen tras la administracion repetida. Otros efectos secundarios como alteraciones gastrointestinales, cambios en libido o reacciones cutáneas han sido comunicados ocasionalmente. Amnesia: Puede aparecer amnesia anterógrada utilizando dosis terapéuticas. Este riesgo aumenta con dosis más altas. La aparición de amnesia puede asociarse con conducta inapropiada (ver 4.4. Adventencias y precauciones). Depresí́n: Una depresión preexistente puede ennmascararse durante el uso d benzodiacepinas o agentes similares a las benzodiacepinas. Reacciones psiquiátricas y «paradójicass: Durante el uso do benzodiacepinas 0 agentes similares a las benzodiacepinas pueden aparecer reacciones cono inquietud, agitación, irritabilldad, agresividad, dellirio, rabia, pesadillas, alucinaciones, psicosis, conducta inapropiada y otros electos adversos sobre la conducir al decarrol lo de dependencia fisica. La intertupción del tratamiento puede provocat fenómenos de rebote o abstinencia (ver 4.4. Advertencias y precauciones). Puede aparecer dependencia psiquica. Se ha informado de abuso en pacientes polimedicados. 4.9. Sobredosificación: Como con otras benzodiacepinas y agentes similares a las benzodiacepinas, la sobredosis no debe presentar una amenaza para la vida excepto cuando se combina con otros depresores de SNC (incluyendo alcohol). En el tratamiento de la sobredosis con cualquier medicamento, se debe tener en cuenta que pueden haber sido ingeridos móltiples agentes. Tras la sobredosis con benzodiacepinas orales o agentes similares a las be nzodlacepinas, se debe inducir el
vómito (en el intervalo de una hora) si el paciente está consciente, o realizar lavado gástrico con protección de las vías respiratorias si el paciente está inconsciente. Si no se produce mejoría con el vaciado del estómago, se administrará carbón activado para reducir la absorción. Se realizará especial supervisión de las funciones respiratoria y cardiovascular en cuidados intensivos. La sobredosis de benzodiacepinas o de agentes similares a las benzodiacepinas se manifiesta habitualmente por
diferentes grados de depresión del sistema nervioso central que van desde la somnolencia hasta el coma. En los casos leves, los sintomas incluyen: somnolencia, confusión méntal y letargia. En casos más graves los síntomas pueden incluir ataxian, hipotonía, hipotensión, depresión respiratoria, raramente coma y muy raramente la muerte. Puede utilizarse como antído1 dumazeni. 5. PROPLOADES HARMACOLOGICAS. 5.1. Propiedades armacodinámicas: Zolpidem, una imidazopirdina, es un agente hipnótico similar a las benzodiacepinas. Se ha demostrado en estudios experimentales que posee efecto están relacionados con un acción agonicto especícica en los receptores centroles pertenecientes al complejo del recepton macromolecular GABA-omega (BZ1 y BZ2) que modula la apertura del canal del ion cloro. Zolpidem actúa principalmen sobre los subtipos de receptor omega (BZ1). La importancia clinica de este hecho no es conocida. 5.2. Propiedades farma cocinéticas: Absorción: Tras la administración oral, la biodisponibilidad de zolpidem es alrededor del $70 \%$, alcanzando el máximo de concentración plasmática entre 0,5 y 3 horas tras la ingesta. Distribución: A dosis terapéuticas, la farmacocince ica es lineal, el grado de unión a proteínas plasmáticas es de alrededor del $92 \%$. La vida media plasmática de eliminación es

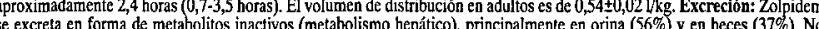
se excreta en forma de metabolitos inactivos (metabolismo hepático), principalmente en orina ( $36 \%$ ) y en heces (37\%). No lasmática está aumentodo aproximadamente el $50 \%$ sin una prolongación significativa de la vida media (alrededor de horas). El volumen de distribución disminuye a $0,34 \pm 0,05 \mathrm{l} / \mathrm{kg}$ en los muy ancianos. En pacientes con insuficiencia renal tanto dializados como no, existe una moderada reducción del aclaramiento. Los otros parámetros farmacocinéticos no se afecan. Biodisponibilidad: En pacientes con insuficiencia hepática, la biodisponibilidad de zolpidem está aumentada, el aclaramiento está reducido y la vida media de eliminación prolongada (aproximadamente 10 horas). 6. DATOS FARMACEUTICOS. 6.1. Relación de excipientess: Núcleo: lactosa, celulosa microcristalina, metilhidroxipropilcelulosa carboximetil almidón sódico, estearato magnesico. Cubierta: metilhidroxipropilcelulosa, dióxido de titanio, polietilenglico servación: Ninguna. 6.5. Naturaleza y contenido del recipiente: Envase con 30 comprimidos en plaquetas blíster PVC-alu-

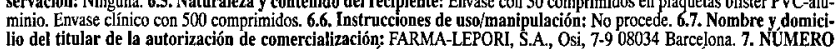
lio del titular de la autorización de comercializacín: FARMA-LEPORI, S.A., Osi, 7-90 08034 . Barcelona. 7. NUMERO
DE REGISTR0.59.264. 8. FECHA DE LA REVISION DEL RCP. Noviembre 1995. PRESENTACIONY PVP. Caja con 30 comprimidos, PVP IVA 4- $4,42 €$. Coste tratamiento/día: $0,14 \in$. Envase clínico: caja con 500 comprimidos. CON RECETA MEDICA. INCLUIDO EN LA SEGURIDAD SOCIAL. APORTACION NORMAL, Licencia del Grupo

El AVP, un ácido carboxílico de cadena ramificada simple, es un anticonvulsionante químicamente diferente de la carbamacepina, y muy probablemente la supresión de las células hematopoyéticas está relacionada con la dosis $[6,7]$. Se encuentra cada vez más trombocitopenia, citopenia y otras formas de toxicidad hematológica en conexión con la administración de AVP, y en algunos casos ha resultado fatal $[1,7]$.

La coadministración de clozapina y AVP puede aumentar ligeramente la concentración en suero de metabolitos de la clozapina [2]. Los informes de la eficacia y la seguridad de la clozapina y el AVP combinados son contradictorios [3, 8]. En nuestro caso, 3 años de monoterapia de clozapina no revelaron efectos secundarios hematológicos, sin embargo, la agranulocitosis se desarrolló después del aumento con AVP y requirió tratamiento de GMC-SF. Informamos de un caso único y debemos ser cautos frente a la generalización y la aplicación errónea de nuestra observación. Se necesita investigación adicional de la terapia combinada de clozapina y AVP.

\section{BIBLIOGRAFÍA}

1 Acharya S, Bussel JB. Hematologic toxicity of sodium valproate. J Pediatr Hematol Oncol 2000;22(1):62-5.

2 Facciola G, Avenoso A, Scordo MG, Madia AG, Ventimiglia A, Perucca E. Small efects of valproic acid on the plasma concentrations of clozapine and its major metabolites in patients with schizophrenic or affective disorders. Ther Drug Monit 1999; 21(3):341-5.

3 Kando JC, Tohen M, Castillo J, Centorrino F. Concurrent use of clozapine and valproate in affective and psychotic disorders. J Clin Psychiatry 1994;55:255-7.

4 Kishi T, Fujita $\mathrm{N}$, Kawaguchi $\mathrm{H}$, Ishimae $\mathrm{M}$, Watanabe $\mathrm{K}$, Tanaka T. Bone marrow suppression induced by high dose valproic acid. Arch Dis Child 1994;71(2):153-5.

5 Luchins DJ. Fatal agranulocytosis in a chronic schizophrenic patient treated with carbamazepine. Am J Psychiatry 1984; 141(5):687-8.

6 MacDougall LG. Pure red cell aplasia associated with sodium valproate therapy. J Am Med Assoc 1982;247(1):53-4.

7 Watts RG, Emanuel PD, Zuckerman KS, Howard TH. Valproic acid-induced cytopenias: evidence for a dose-related suppression of hematopoiesis. J Pediatr 1990; 117(3):495-9.

8 Wilson W. Do anticonvulsants hinder clozapine treatment. Biol Psychiatry 1995;37:132-3. 